\title{
Modeling of mechanical behavior of cork in compression
}

\author{
Younès Saadallah \\ University of Mohamed Seddik Ben Yabia, Jijel, Algeria \\ sayounes@live.fr, bttp://orcid.org/0000-0003-1265-3677
}

\begin{abstract}
The present work consists of a contribution in modeling the mechanical behavior of cork in compression. For this purpose, compression tests are performed in the non-radial direction on high density reproduction cork samples. Cork shows stress-strain curves, typical of cellular materials, characterized by an elastic slope followed by an important plateau corresponding to buckling of cells; and finally hardening due to the densification of the material. Two behavior models are proposed to represent this behavior. A trilinear model in which each slope represents one of the three domains and whose parameters are identified directly from the stressstrain curves. A more nonlinear model corresponding to a third-order polynomial whose parameters are identified by means of a polynomial regression. Test-model comparisons reveal little relevance of the results given by the trilinear model whereas a very good consistency is observed for the results given by the nonlinear model.
\end{abstract}

KEYWORDS. Cork; Compression; Behavior model; Parameters identification; Stress-strain.

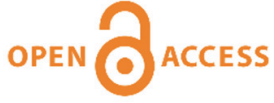

Citation: Saadallah, Y., Modeling of mechanical behavior of cork in compression, Frattura ed Integrità Strutturale, 53 (2020) $417-425$
\end{abstract}

Received: 13.05 .2020

Accepted: 02.06.2020

Published: 01.07.2020

Copyright: (C) 2020 This is an open access article under the terms of the CC-BY 4.0, which permits unrestricted use, distribution, and reproduction in any medium, provided the original author and source are credited.

\section{INTRODUCTION}

C hoosing the right materials to use to perform specific functions is always a very important step. Different criteria are then taken into account, including cost and properties; but also, their impact on the environment. Environmental protection has become a major issue in recent times, it is extremely vital to look for ecological materials. Among these are natural materials including wood and cork.

Cork is a natural product obtained from the outer bark of an oak species, the cork oak. The cork layers that are produced in its bark form a continuous envelope with appreciable thickness around the trunk and branches. The cork can be removed from the stem without endangering the vitality of the tree, which then rebuilds a new layer of cork. This is the basis of sustainable cork production during the long life of cork oak [1]. Lightness, high compressibility, dimensional recovery, thermal and sound insulation, very low permeability to liquids and gases and chemical stability are properties that make cork a widely used material in various applications [2-6]. The cost of this material is also an attractive factor. These so particular properties, still little explained, strongly encourage further research.

The elastic properties of cork have been studied by several researchers. Gibson et al [5] focused on the identification of elastic parameters in the three radial, axial and tangential directions. The elastic modulus, the shear modulus and the 
Poisson's ratio have been determined. The results obtained show that cork is almost isotropic in non-radial directions. However, it has a larger Young's modulus and a zero Poisson's ratio when it is stressed in the radial direction. Oliveira et al. [7], studied the variability of the compressive properties of cork. The results show that the radial direction has the greatest compressive strength while the resistance in the axial and tangential directions is almost similar. Anjos et al. [8] investigated the effect of density on the properties of cork in compression. This results in an increase of the Young's modulus with the increase of the density especially beyond the elastic region. García et al. [9] have sought a compression model linking physical properties (porosity, density and test direction) to mechanical properties using a classical linear regression technique.

The compressive strain stress curves reveal an elastic domain at (5-7) \% followed by a large plateau for strains caused by the progressive buckling of the cell walls until a strain of (50-70) \%, and a steep stress increase for higher strains corresponding to cell collapse $[5,7,8,10]$. Cork has the distinction of having an insignificant Poisson's ratio [2]. This is explained by its nature and highly porous and cellular structure. Indeed, cork has the ability to undulate its cell walls when it is compressed and thus it can have a large longitudinal compression deformation without lateral expansion [10]. Complete densification corresponds to $85 \%$ strain without fracture [7]. Indeed, the fracture occurs in the case of a tensile stress. After the removal of the load, the cork recovers. The rate of recovery decreases over time [11]. For a strain level of $50 \%$, half of the dimensions recover after the first day and end at $90 \%$ in the fifteenth day [8]. For a strain level of 30\%, the recovery is total after 20 days of removal of the load [11] while it is not total for a level exceeding $80 \%$.

The behavior of the tensile cork in the tangential and axial direction has been studied respectively in the references $[12,13]$. It follows that the tensile strength in the tangential direction is lower than that in the axial direction. In comparison with its compression behavior, cork has a lower tensile elastic domain. This area is around $2 \%$ in both tangential and axial directions. The fracture takes place respectively in the tangential and axial directions at 5\% and $7.1 \%$. On the other hand, in the radial direction, it corresponds to an $18 \%$ strain value [14]. It follows that the resistance of the cork is much greater in the radial direction as well in compression as in traction.

Many studies have focused on the analysis of cork behavior through its parameters such as the Young's modulus, the elastic limit and the stresses corresponding to certain critical strain values [5, 7-9, 11-13]. However, few of them have focused on the proposal of models to predict the overall behavior of cork.

The present work is a contribution in the modeling of the mechanical behavior of cork in compression. To do this, compression tests are conducted in the non-radial direction. On the basis of qualitative analysis of stress-strain curves, two models of behavior are proposed: a trilinear model and nonlinear model. The parameters that manage these models are identified. Model test comparisons are presented and discussed.

\section{EXPERIMENTAL PROTOCOL}

\section{Material of study}

7 he material of study is a cultivated breeding cork from the forests of the Jijel area in Algeria. The cork plank (reproduction cork) obtained are wetted in boiled water at atmospheric pressure for $1 \mathrm{~h}$ and left to air-dry to get rid of any impurities. It is a procedure widely applied in the cork industry. Specimens are cut into cubes of $20 \mathrm{~mm}$ on the side, with their faces perpendicular to each of the three main directions. (Fig. 1). This geometry is chosen for the sake of conformity with previous works, including, for example, references [7, 9]. The density was measured from the volume and weight in $\mathrm{g} \cdot \mathrm{cm}^{-3}$.

\section{Experimental procedure}

The compression tests in the non-radial direction were done at a constant crosshead speed of $2 \mathrm{~mm} . \mathrm{min}^{-1}$. The test machine is a Zwick 1476 with a capacity of $100 \mathrm{kN}$ (Fig. 2) driven by software suitable for computer control of the test. The test conditions are summarized in a temperature of $26{ }^{\circ} \mathrm{C}$ and a relative humidity of $30 \%$.

\section{Behavior modeling}

As illustrated in Fig. 3, the stress-strain curves obtained from a compression test on a sample show a three-domain behavior: first, an elastic domain; then a domain of buckling cells with low slope; finally, a densification area with a high slope. In the light of these findings, two approaches are proposed, in this work, to predict the behavior of cork in compression: linear and nonlinear.

The linear approach considers that the behavior is linear throughout its evolution where the three domains are modeled by lines of different slopes. Average slopes are represented by the following formulas: 
$E=\sigma_{e} / \varepsilon_{e} ; F=\left(\sigma_{f}-\sigma_{e}\right) /\left(\varepsilon_{f}-\varepsilon_{e}\right) ; D=\left(\sigma_{d}-\sigma_{f}\right) /\left(\varepsilon_{d}-\varepsilon_{f}\right)$
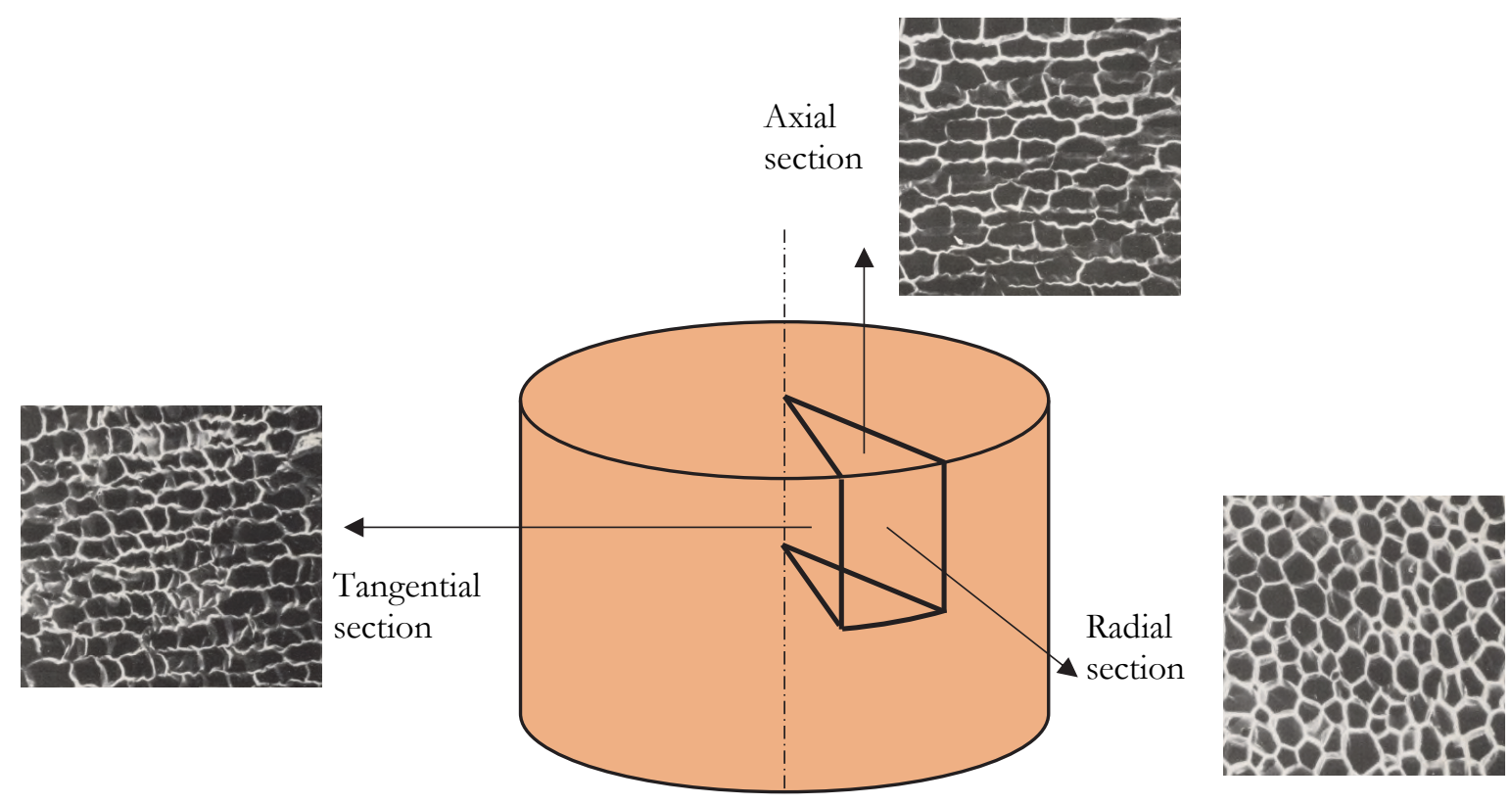

Figure 1: Scanning electron micrographs of the three sections of cork [5].

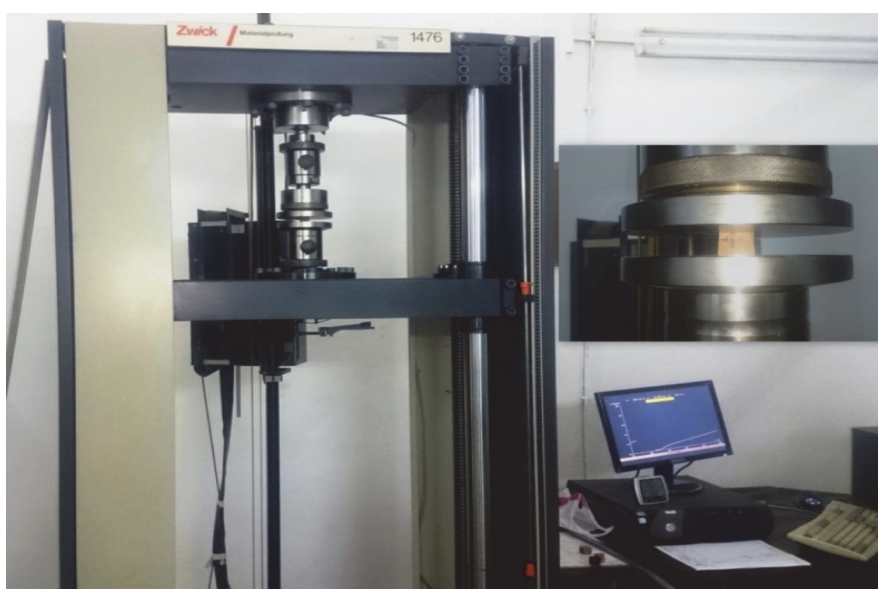

Figure 2: Test set-up and cork specimen.

where E, F, D are respectively the slopes of the three different domains. $\sigma_{e}, \sigma_{f}, \sigma_{d}$ and $\varepsilon_{e} \cdot, \varepsilon_{d}$ represent respectively the stresses and strains at the boundaries of each of the three domains. So, we write the behavior model as follows:

$$
\left\{\begin{array}{lr}
\sigma=E \varepsilon & \sigma \leq \sigma_{e} \\
\sigma=\sigma_{e}\left(\frac{E-F}{E}\right)+F \varepsilon & \sigma_{e} \leq \sigma \leq \sigma_{f} . \\
\sigma=\sigma_{e} D\left(\frac{E-F}{E F}\right)+\sigma_{f}\left(\frac{F-D}{F}\right)+D \varepsilon & \sigma_{f} \leq \sigma \leq \sigma_{d}
\end{array}\right.
$$


$\sigma$ and $\varepsilon$ being respectively the stress and the strain, the parameters are determined by a direct linear regression from the stress-strain curves.

In addition, the nonlinear approach states that the behavior is non-linear in all domains. A polynomial of three degrees with four parameters is proposed.

$$
\sigma=A \varepsilon^{3}-B \varepsilon^{2}+C \varepsilon+K
$$

where $\mathrm{A}, \mathrm{B}, \mathrm{C}$ and $\mathrm{K}$ are positive parameters; $\sigma$ and $\varepsilon$ are respectively the stress and the strain.

Since the polynomial is nonlinear of third order, recourse to numerical computation is necessary for the determination of its parameters. A polomial regression was favored to identify the behavior.

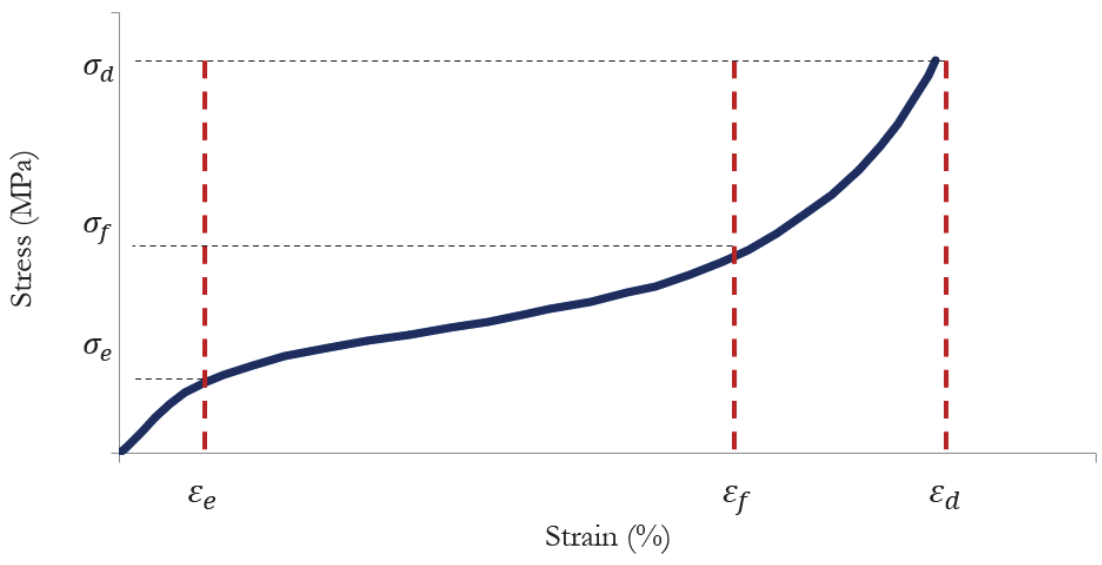

Figure 3: Typical stress-strain curve of cork in compression.

\section{RESULTS AND DISCUSSION}

^r

he discussion of the results consists of a comparative study of the results obtained by the two models proposed. The identified parameters are presented and discussed. Test-model confrontations are put in place to judge the relevance of the results.

\section{Stress-strain curves aspect}

Fig. 4 illustrates the mechanical behavior of a sample of cork in compression in the non-radial direction. There are three domains that will be called elastic domain, buckling domain and densification domain. The elastic domain spreads at a strain of 7\% while the buckling domain of the cells is limited to about 55\% strain for all densities. Density is one of the parameters that influences cork resistance behavior [8, 15]. It is noted that this influence is apparent especially in buckling and densification levels. It should be emphasized that density is not the only factor to govern the behavior of cork. Other factors, such as porosity, quality [12], also have a significant effect on the strength of the material.

\section{Linear model}

Since the behavior is trilinear, it is governed by three parameters representing the slopes of the lines and two other parameters corresponding to the limit stresses of the elastic and buckling domains as illustrated in Fig. 3. The results of the parameters obtained are summarized in Tab. 1. In sum, the parameters of the least dense sample are small compared to the parameters of the other two samples. It is also noted that the slopes of the buckling domains $\mathrm{F}$ and densification $\mathrm{D}$ are largest for the densest sample.

It should be mentioned that the stress $\sigma_{d}$. is not a significant parameter because it only corresponds to the end of the test. However, it can provide us with information on the stress corresponding to the final strain of the test which is $66.9 \%$.

The injection of these parameters into the trilinear behavior model formulated in Eqn. (2) makes it possible to compare the model test results as illustrated in Fig. 5. Good consistency in the elastic domain is observed. Indeed, the elastic domain is linear for most materials. Linearity is maintained at the beginning of the buckling step or the pace changes to nonlinear moving towards the densification zone. A relatively large gap appeared in the intersection of the buckling and densification 
domains. The slope of the densification domain exhibits the strongest nonlinearity by comparing it with the other two domains.

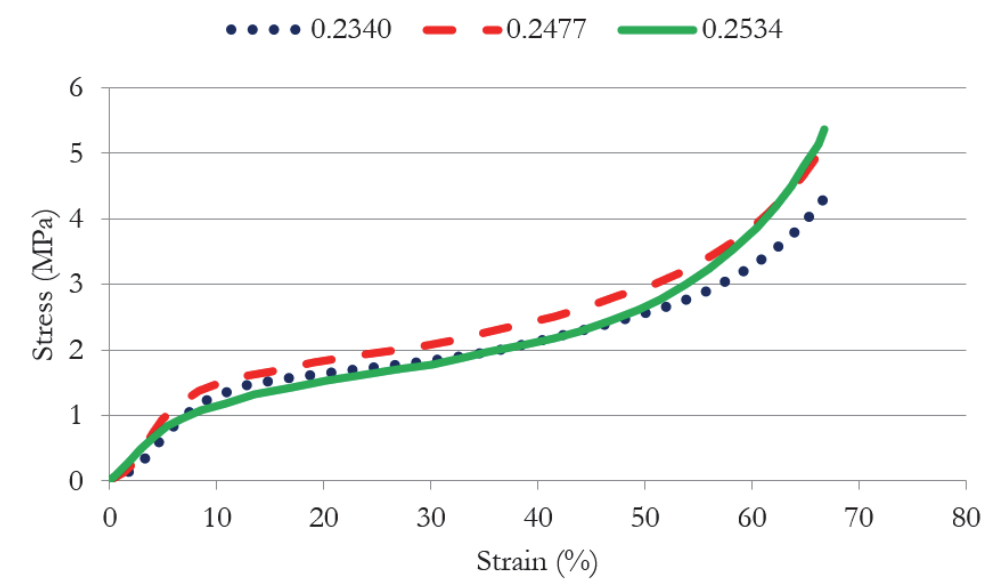

Figure 4: Stress-strain curves in compression in the non-radial direction of cork at different densities.

\begin{tabular}{llll}
\hline Density $\left(\mathrm{g} / \mathrm{cm}^{3}\right)$ & 0.2340 & 0.2477 & $\mathbf{0 . 2 5 3 4}$ \\
$\mathrm{F}(\mathrm{MPa})$ & 2.85 & 3.33 & 15.5 \\
$\mathrm{D}(\mathrm{MPa})$ & 13.2 & 16.5 & $\mathbf{3 . 4 5}$ \\
$\sigma_{e} \cdot(\mathrm{MPa})$ & 1.3 & $\mathbf{1 . 4}$ & $\mathbf{2 0}$ \\
$\sigma_{f} \cdot(\mathrm{MPa})$ & 2.55 & $\mathbf{2 . 9}$ & 1.1 \\
$\sigma_{d}$ at $66.9 \%(\mathrm{MPa})$ & 4.36 & 5.16 & $\mathbf{2 . 7}$ \\
\hline
\end{tabular}

Table 1: Trilinear model parameters as a function of density.

Fig. 6 shows the difference in absolute value between the experimental recordings and the model results for the three samples of different densities. There is a minimum difference in the elastic range and the buckling step with a maximum value of $0.14 \mathrm{MPa}$. However, the intersection of the straight lines of buckling and densification knows a significant gap that reaches $0.29 \mathrm{MPa}$. It retains its importance in the field of densification where it reaches its maximum value of $0.29 \mathrm{MPa}$ as well. As a function of density, the highest difference is found in the densest sample.

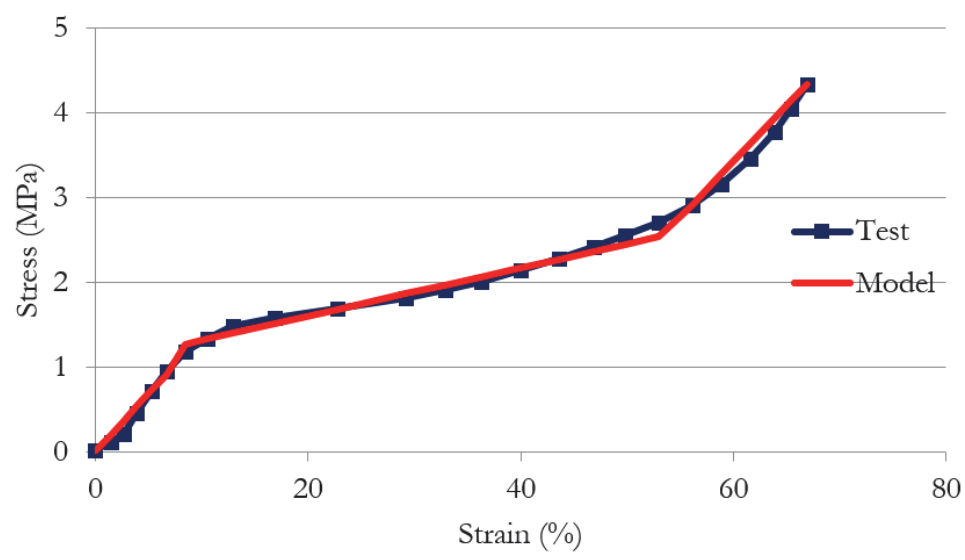

(a) 


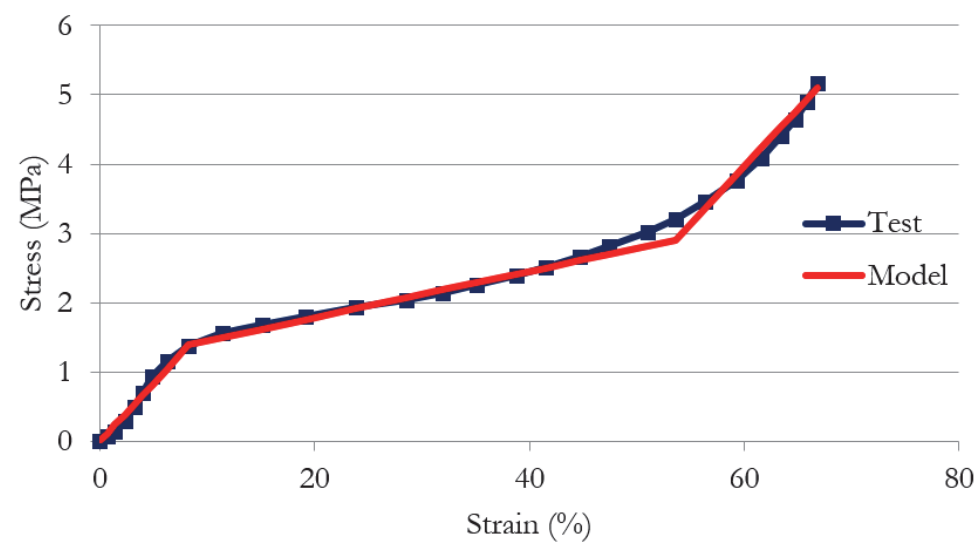

(b)

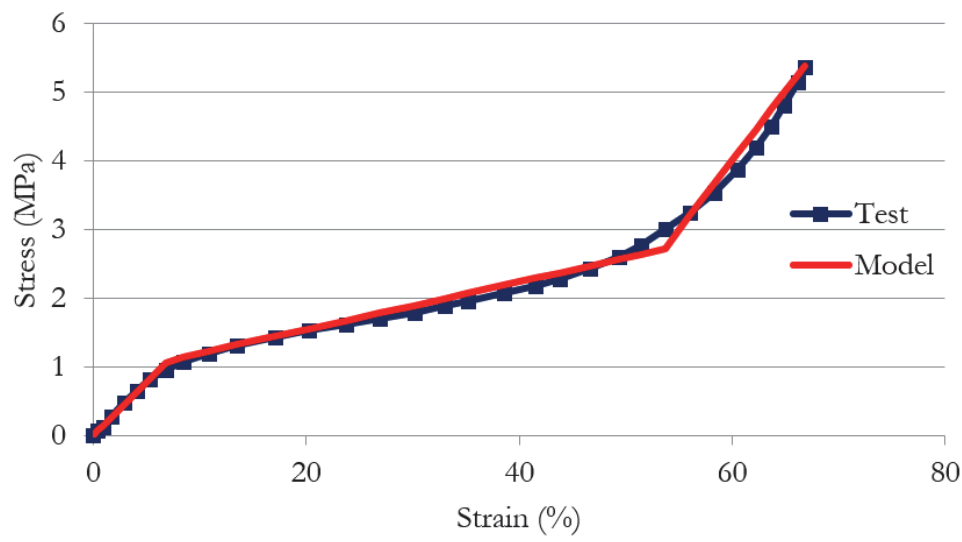

(c)

Figure 5: Linearization of cork behavior in compression at different densities in g.cm $^{-3}$ : a) 0.2340 ; b) 0.2477 ; c) 0.2534 ).

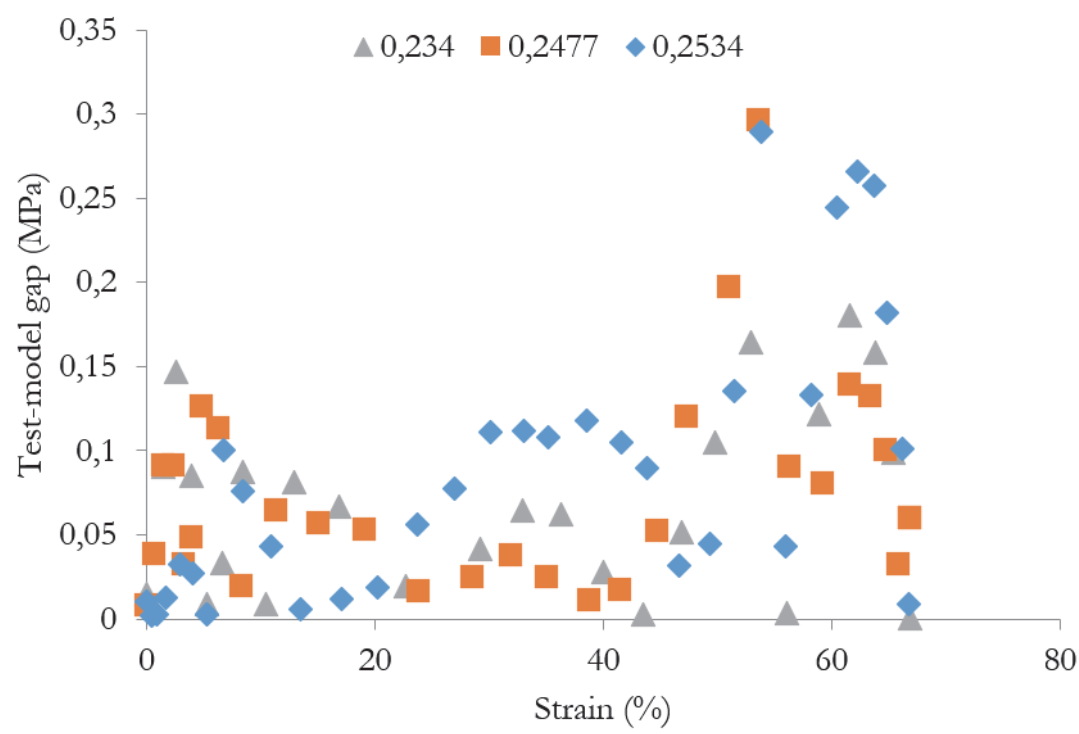

Figure 6: Test-model gap.

\section{Nonlinear model}

The nonlinear model is a third-order polynomial driven by four parameters. These parameters are identified by means of a polynomial regression and are presented in Tab. 2. It is noted that the parameter A is independent of the density while the 
other three depend on it weakly. This low dependence probably results from the small difference in the densities of the samples. It would therefore be interesting to plan other studies with samples of remarkably different densities.

\begin{tabular}{cccc}
\hline Density $\left(\mathrm{g} / \mathrm{cm}^{3}\right)$ & 0.2340 & 0.2477 & 0.2534 \\
A $(\mathrm{MPa})$ & $5.10^{-5}$ & $5.10^{-5}$ & $5.10^{-5}$ \\
$\mathrm{~B}(\mathrm{MPa})$ & 0.0044 & 0.0049 & 0.0045 \\
$\mathrm{C}(\mathrm{MPa})$ & 0.1583 & 0.1722 & 0.1456 \\
$\mathrm{~K}(\mathrm{MPa})$ & 0.0234 & 0.0445 & 0.0641 \\
\hline
\end{tabular}

Table 2: Nonlinear model parameters by density.

Fig. 7 establishes a test-model comparison between stress-strain curves of cork in compression in a non-radial direction. There is a very good consistency of the results with the nonlinear model in the three domains, but even better in the densification domain. In contrast to the case of the tri-linear model, there is a minimum difference in the densest sample. By deriving the polynomial of the loading with respect to the strain in the case of the nonlinear model, we obtain the loading derivative. Fig. 8 shows us that this derivative decreases up to $30 \%$ of deformation where it reaches its minimum value. This minimum can be considered as another parameter of the cork from which the material hardens and thus the loading derivative increases until the end of the test.

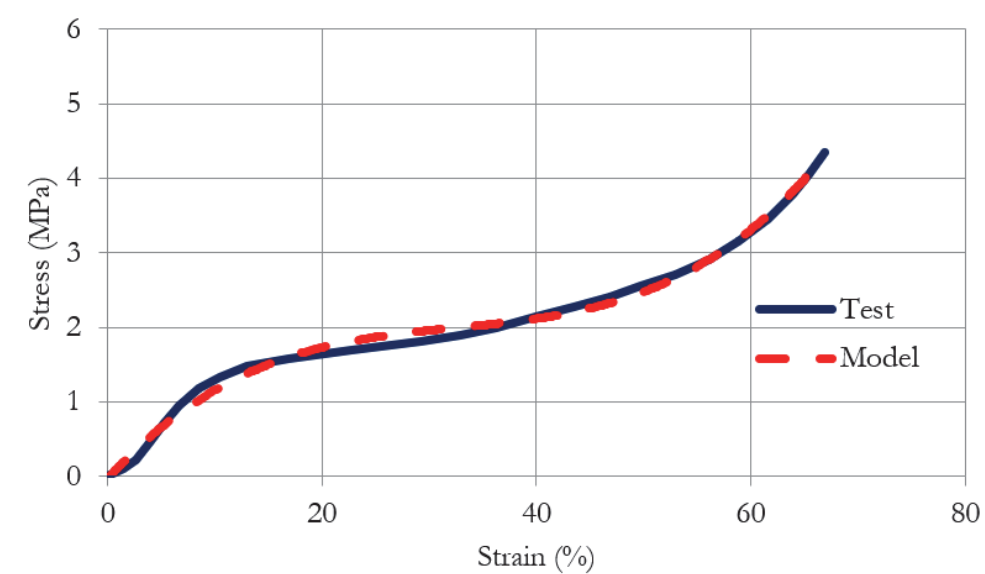

(a)

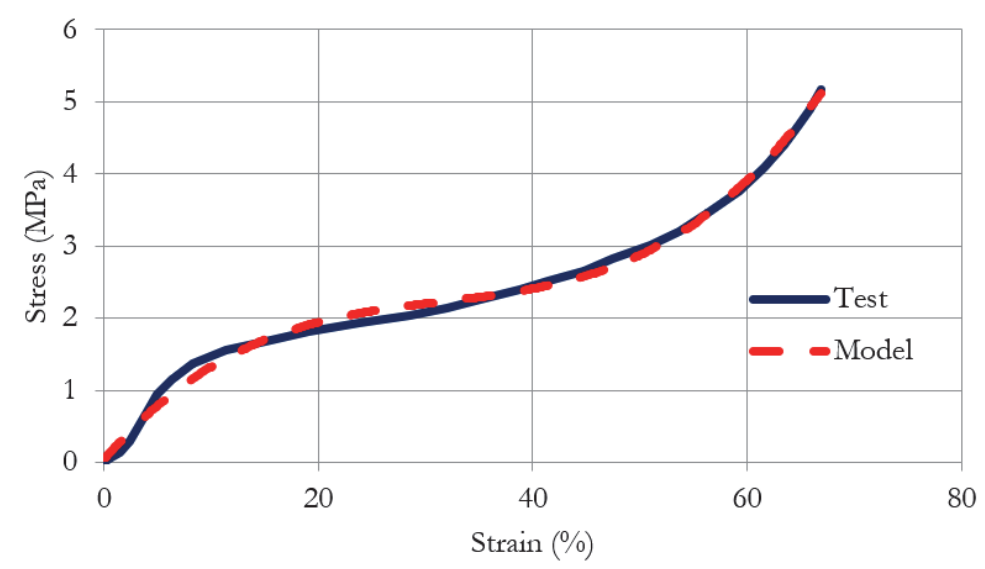

(b) 


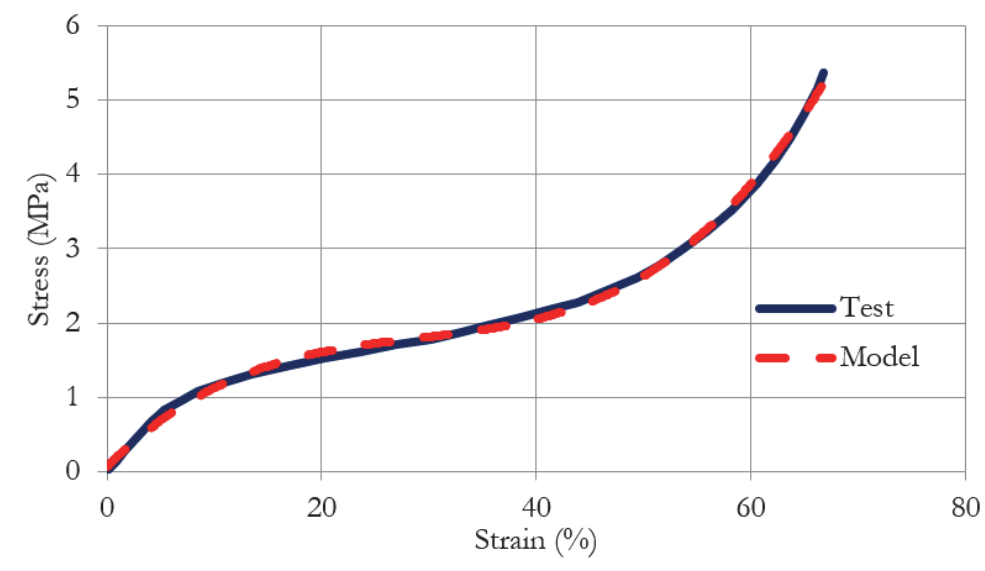

(c)

Figure 7: Nonlinear behavior of cork in compression at different densities in g.cm ${ }^{-3}:$ a) 0.2340 ; b) 0.2477 ; c) 0.2534 ).

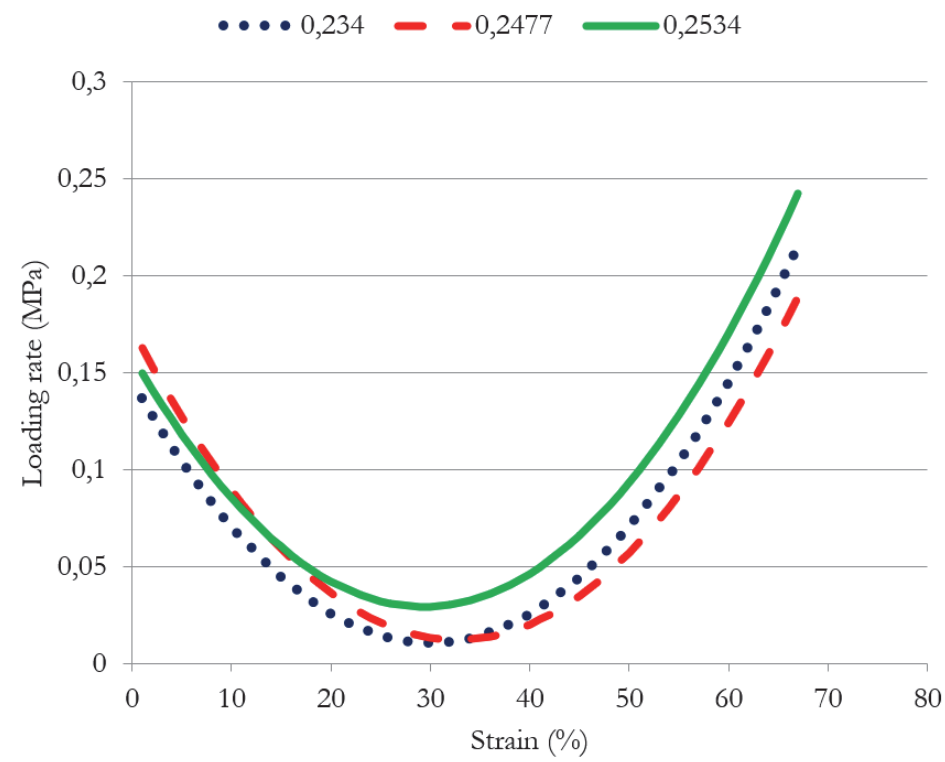

Figure 8: Evolution of the loading derivative.

\section{CONCLUSION}

7 he present work aimed to establish two models for the representation of the behavior of cork in compression. Compression tests were conducted on cubic samples of cork in the non-radial direction. The shape of the curves with three domains made it possible to propose first a trilinear model of which each domain is represented by a slope. Then, another non-linear model with four parameters was put in place. The parameters of the trilinear model are determined by direct linear regression from the stress-strain curves while those of the nonlinear model required a third order polynomial regression. The comparison of test-model results reveals that the nonlinear model is more refined and has fewer parameters than the trilinear model. It was concluded that the trilinear model, being relatively crude, is suggested to fulfill educational functions. However, the nonlinear model, because of its relevance, can serve as a tool of choice to exploit in the field of behavior modeling of materials.

\section{REFERENCES}

[1] Pereira, H. (2011). Cork: biology, production and uses, Elsevier. 
[2] Silva, S., Sabino, M., Fernandes, E., Correlo, V., Boesel, L. and Reis, R. (2005). Cork: properties, capabilities and applications, International Materials Reviews, 50, pp. 345-365, DOI:10.1179/174328005X41168.

[3] Mano, J. (2007). Creep-recovery behaviour of cork, Materials Letters, 61, pp. 2473-2477, DOI: $10.1016 /$ j.matlet.2006.03.157.

[4] Knapic, S., Oliveira, V., Machado, J. S. and Pereira, H. (2016). Cork as a building material: a review, European Journal of Wood and Wood Products, 74, pp. 775-791, DOI: 10.1007/s00107-016-1076-4.

[5] Gibson, L., Easterling, K. and Ashby, M. F. (1981). The structure and mechanics of cork, Proceedings of the Royal Society of London. A. Mathematical and Physical Sciences, 377, pp. 99-117, DOI: 10.1098/rspa.1981.0117.

[6] Gil, L. (2015). Cork, in Materials for construction and civil engineering, ed: Springer, pp. 585-627.

[7] Oliveira, V., Rosa, M. E. and Pereira, H. (2014). Variability of the compression properties of cork, Wood science and technology, 48, pp. 937-948, DOI: 10.1007/s00226-014-0651-2.

[8] Anjos, O., Rodrigues, C., Morais, J. and Pereira, H. (2014). Effect of density on the compression behaviour of cork, Materials \& Design, 53, pp. 1089-1096, DOI: 10.1016/j.matdes.2013.07.038.

[9] García, Á., Anjos, O., Iglesias, C., Pereira, H., Martínez, J. and Taboada, J. (2015). Prediction of mechanical strength of cork under compression using machine learning techniques, Materials \& Design, 82, pp. 304-311, DOI: $10.1016 /$ j.matdes.2015.03.038.

[10] Pereira, H. (2015). The Rationale behind Cork Properties: A Review of Structure and Chemistry, 10, p. 1-23, DOI: $10.15376 /$ biores.10.3.Pereira.

[11] Rosa, M. E. and Fortes, M. A. (1988). Rate effects on the compression and recovery of dimensions of cork, Journal of Materials Science, 23, pp. 879-885, DOI: 10.1007/BF01153983.

[12] Anjos, O., Pereira, H. and Rosa, M. E. (2010). Tensile properties of cork in the tangential direction: variation with quality, porosity, density and radial position in the cork plank, Materials \& Design, 31, pp. 2085-2090, DOI: $10.1016 /$ j.matdes.2009.10.048.

[13] Anjos, O., Pereira, H. and Rosa, M. E. (2011). Tensile properties of cork in axial stress and influence of porosity, density, quality and radial position in the plank, European Journal of Wood and Wood Products, 69, pp. 85-91, DOI: /10.1007/s00107-009-0407-0.

[14] Rosa, M. E. and Fortes, M. A. (1991), Deformation and fracture of cork in tension, Journal of Materials Science, 26, pp. 341-348, DOI: $10.1007 /$ BF00576525.

[15] Anjos, O., Pereira, H. and Rosa, M. E. (2008), Effect of quality, porosity and density on the compression properties of cork, Holz als Roh-und Werkstoff, 66, p. 295-301, DOI: 10.1007/s00107-008-0248-2. 